\title{
Growth of Preexisting Abnormal Grains in Molybdenum under Static and Dynamic Conditions
}

\author{
Philip J. Noell ${ }^{\mathrm{a}}$, Daniel L. Worthington ${ }^{\mathrm{b}}$, Eric M. Taleff ${ }^{\mathrm{c}}$ \\ ${ }^{a}$ Sandia National Laboratories, P.O. Box 5800, Albuquerque, NM 87185-0889, USA. \\ ${ }^{b}$ Fujifilm Dimatix, Inc., 2250 Martin Ave., Santa Clara, CA 95050, USA. \\ ${ }^{c}$ The University of Texas at Austin, Department of Mechanical Engineering, 204 East Dean Keeton St., Stop C2200, \\ Austin, TX 78712, USA.
}

\begin{abstract}
This investigation compares the growth rates of preexisting abnormal grains under both static and dynamic conditions. Abnormal grains several millimeters in length were produced in two commercial-purity molybdenum (Mo) materials by tensile straining at temperatures from 1923 to $2073 \mathrm{~K}\left(1650\right.$ to $\left.1800^{\circ} \mathrm{C}\right)$. This process is termed dynamic abnormal grain growth (DAGG) because it produces abnormal grains during concurrent plastic straining. DAGG creates abnormal grains at much lower temperatures than does static abnormal grain growth (SAGG). Abnormal grains created through DAGG were characterized with their surrounding microstructures and were then subjected to annealing treatments. Only one-third of the preexisting abnormal grains subsequently grew by SAGG. Among these, SAGG occurred only in those specimens that required the largest strains to initiate DAGG when creating the abnormal grain(s). The rates of boundary migration observed for SAGG were approximately two orders of magnitude slower than those for DAGG. When DAGG in one specimen was interrupted by extended static annealing, it did not recur when straining resumed. The dislocation substructure developed during hot deformation, which includes subgrains typical of five-power creep, is critically important to both DAGG and SAGG of preexisting abnormal grains under the conditions examined.

Keywords: grain growth, grain boundaries, recrystallization, plasticity, refractory metal
\end{abstract}

\footnotetext{
* Corresponding author

Email address: taleff@utexas.edu (Eric M. Taleff)
} 


\section{Introduction}

Abnormal grain growth (AGG) is the process of one or more grains growing to be significantly larger than grains of the surrounding microstructure [1,2]. These large grains are called abnormal grains. AGG often produces a bimodal microstructure consisting of several abnormally large grains surrounded by many smaller grains. In extreme cases, abnormal grains can consume the entire microstructure to produce a uniformly coarse grain size or even a single crystal [2-7]. AGG is thus of interest for producing single crystals in the solid state, a capability demonstrated in the laboratory for molybdenum (Mo) [8-14] and tantalum (Ta) [15]. For grain-oriented silicon steels, AGG is desired and necessary to produce the coarse, highly-textured microstructures required for optimal performance in electrical transformers [16]. In other cases, such as the Ni-based superalloys used in jet engines, the large grains produced by AGG can be quite detrimental [17-22]. The accidental occurrence of AGG during thermomechanical processing must be avoided for such materials. These are some of the many reasons to seek a predictive understanding of AGG phenomena, which are to date only understood in quite basic terms [23].

AGG phenomena may be divided into two broad categories [10,11]: AGG that occurs during static annealing at elevated temperature, termed static abnormal grain growth (SAGG), and AGG that occurs during concurrent plastic deformation at elevated temperature, termed dynamic abnormal grain growth (DAGG). SAGG is synonymous with the behavior called secondary recrystallization $[1,2]$. DAGG is a recently discovered phenomenon that produces AGG at lower temperatures than does SAGG. For the case of commercial-purity Mo sheet materials, DAGG was observed at approximately $1773 \mathrm{~K}\left(1500^{\circ} \mathrm{C}\right)$ and has been repeatedly produced at $1923 \mathrm{~K}\left(1650^{\circ} \mathrm{C}\right)[10-12]$. SAGG, however, has only been observed in Mo at temperatures of $2073 \mathrm{~K}\left(1800^{\circ} \mathrm{C}\right)$ and higher $[8,24]$. Important features of DAGG are illustrated in Figure 1. This figure presents data from a tensile test at $1923 \mathrm{~K}\left(1650^{\circ} \mathrm{C}\right)$ and a true-strain rate of $10^{-4} \mathrm{~s}^{-1}$ for the commercial-purity Mo sheet material examined in the present study. During initial tensile straining, the specimen displays high-temperature plasticity typical of creep deformation. Upon reaching the critical strain for DAGG initiation, $\varepsilon_{\mathfrak{c}}$, which is 0.13 for the data in Figure 1, DAGG initiates and causes a concurrent sharp drop in flow stress. Plastic straining immediately beyond $\varepsilon_{\mathrm{c}}$ continues the growth by DAGG of the abnormal grain(s) initiated at $\varepsilon_{\mathrm{c}}$, typically until the entire microstructure of the specimen gauge region is consumed. Once the entire gauge region is consumed by one or more ab- 
normal grains, DAGG is complete and the flow stress stabilizes at a value significantly lower than before $\varepsilon_{\mathrm{c}}$. Abnormal grains do not grow into the undeformed grip region of the tensile coupon. Continued straining simply deforms the abnormal grain(s) spanning the specimen gauge region until specimen rupture. When tensile deformation is halted prior to DAGG completion, DAGG also ceases. This produces one or more abnormal grains, such as the one shown in Figure 1, that span only part of the specimen gauge region.

The reasons why SAGG is only observed at temperatures significantly above those for which DAGG occurs are not well understood. An important first step toward better understanding both DAGG and SAGG is to differentiate between the initiation, sometimes termed nucleation, of abnormal grains and their subsequent growth. The failure of SAGG to produce abnormal grains in Mo below $2073 \mathrm{~K}\left(1800^{\circ} \mathrm{C}\right)$ could be because of either an inability to initiate abnormal grains at these relatively low temperatures $\left(T_{\mathrm{H}}<0.72\right)$ or an extremely slow growth rate following initiation. The question of relative growth rates between SAGG and DAGG in the same material at identical temperatures has not been previously investigated. This study addresses this question by using DAGG to initiate abnormal grains, such as that shown in Figure 1, and then studying the subsequent growth of these preexisting abnormal grains under both static and dynamic conditions.

Prior investigations demonstrated the importance of grain-boundary curvature and concurrent plastic deformation in the growth of abnormal grains by DAGG [10-15]. Grain-boundary curvature was demonstrated to supply the most important driving force for DAGG in Mo, and concurrent deformation is thought to primarily increase boundary mobility during DAGG [11-13]. However, the critical strains required for DAGG initiation indicate that significant dislocation substructure likely forms within the interiors of deformed grains prior to DAGG [25]. This may affect boundary migration in other ways. To address this possibility, specimens for this study were statically annealed following the initial creation of abnormal grains in order to eliminate as much of the dislocation substructure from the unconsumed, deformed polycrystalline microstructure as is practical through recovery. It will be shown that this met only limited success. The annealed specimens were then tested to investigate the potential for further growth of the preexisting abnormal grains created through DAGG. The following two specific questions are probed: 1. will a preexisting abnormal grain grow by SAGG during static annealing, and 2. will a preexisting abnormal grain in an annealed specimen grow again by DAGG when hot deformation is resumed? Where growth of 
preexisting abnormal grains was observed, measurements of boundary migration rates were made.

To avoid the complications produced by normal grain growth, this study uses a commercialpurity Mo sheet material that resists normal grain growth at temperatures up to $2073 \mathrm{~K}\left(1800{ }^{\circ} \mathrm{C}\right)$ $[11,12]$. This facilitates meaningful comparisons between tests at different temperatures and after different annealing times. To observe the effect of crystallographic texture on the growth of abnormal grains, an additional test used a separate commercial-purity Mo material in rod form with a deformation texture different from that of the sheet material.

\section{Experimental}

To study the growth of abnormal grains in Mo, DAGG was used to produce abnormal grains in two commercial-purity Mo materials, one in sheet form and the other in rod form. Individual specimens of the Mo sheet and rod materials are designated as Mo S and Mo R, respectively, with a different number appended for each specimen. Powder-metallurgy techniques were used to fabricate the Mo sheet material. This material meets the ASTM B 386, Grade 361 specification for commercially-pure Mo [26] and is the same sheet material designated as Mo PMB in a previous study by Noell et al. [12]. This sheet material was rolled to the as-received thickness of $0.76 \mathrm{~mm}$, and the final rolling direction was used as a reference for the orientations of tensile test specimens. The chemical composition of the Mo sheet was evaluated by Noell et al. [12] and is provided in Table 1. The Mo rod material was produced using arc-melting techniques. The composition of the Mo rod prior to machining, provided by the manufacturer, is also shown in Table 1.

Creating abnormal grains by DAGG requires plastic deformation at high temperatures. For this first step in the study, tensile specimens of each Mo material were produced. Pin-loaded tensile coupons of the Mo sheet material were machined from the as-received Mo sheet. The gauge length

and gauge width of the Mo sheet specimens were $25.4 \mathrm{~mm}$ and $6.4 \mathrm{~mm}$, respectively. The radius between the grip and gauge regions was $1.6 \mathrm{~mm}$. Specimens of the Mo sheet material retained the as-received thickness of $0.76 \mathrm{~mm}$. The specimen axes for the Mo sheet specimens are defined as the tensile direction (TD), the tensile long transverse direction (TLTD) and the short transverse direction (STD); see Figure 2(a). The TD of the Mo sheet specimens was perpendicular to the final sheet rolling direction (RD). One specimen of the Mo rod material was tested in tension using a pin-loaded configuration. This specimen was machined to have a gauge length of $31.6 \mathrm{~mm}$, a gauge 
diameter of $6.4 \mathrm{~mm}$ and a radius of $5.1 \mathrm{~mm}$ between the grip and gauge regions. The specimen axes of this Mo rod specimen are defined as the tensile direction (TD) and the radial direction (RAD); see Figure 2(b). Tensile specimens from the Mo sheet material remained entirely within the furnace hot zone during testing. Pins of silicon carbide were used to attach these specimens to tungsten pull rods that exited the furnace through bellows assemblies. The gauge region of the Mo rod tensile specimen remained entirely within the furnace hot-zone during testing. The grip regions of the Mo rod tensile specimen exited the furnace hot zone and were attached by pins to TZM Mo pull rods that exited the furnace through bellows assemblies.

To create abnormal grains by DAGG, uniaxial tension tests were performed at true-strain rates of $10^{-4}$ and $10^{-3} \mathrm{~s}^{-1}$ and temperatures from 1923 to $2073 \mathrm{~K}\left(1650\right.$ to $\left.1800^{\circ} \mathrm{C}\right)$. These tests were performed using an MTS Systems (Eden Prairie, MN) Alliance RF/100 computer-controlled, electromechanical testing frame fitted to a Thermal Technology LLC (Santa Rosa, CA) Testmaster 3-8-3-W vacuum furnace. To conduct tensile tests at constant true-strain rates, the cross-head displacement rate of the load frame was continuously varied during testing through computer control. This method assumed uniform specimen deformation and constant volume within the gauge length during testing. These assumptions were valid for the Mo sheet material for strains of up to nearly specimen rupture. The Mo rod material, however, necked significantly during testing. The truestrain rate in the Mo rod material could not be accurately calculated after necking began. The force on the pull rods connected to the tensile specimen was monitored throughout each tensile test by a load cell outside the furnace. These force data were corrected after testing to remove the load from the bellows that seal the load train into the furnace. The displacement of the cross-head was also monitored throughout each test. The force and displacement data were used to calculate true stress and true strain during testing, assuming uniform specimen elongation. A vacuum of approximately $10^{-4} \mathrm{~Pa}\left(10^{-6}\right.$ torr) was routinely achieved during testing. The furnace hot zone was heated to the desired testing temperature within fifteen minutes and controlled to within $\pm 10 \mathrm{~K}$ of the set temperature throughout testing. Following heating to the testing temperature, each tensile specimen was held at the testing temperature under a light load until the rate of thermal expansion from the load train was less than $10^{-5} \mathrm{~mm} / \mathrm{s}$. A minimum of 1 hour was necessary for this to occur, but times of up to $2 \mathrm{hrs}$ were required for some specimens. These procedures were intended to minimize the effects of thermal expansion on cross-head displacement data and the subsequent 
calculations of strain.

The testing temperature, true-strain rate and final true strain $\left(\varepsilon_{\mathrm{f}}\right)$ of each tensile test for abnormal grain production are provided in Table 2. DAGG initiation was confirmed during each tension test by the characteristic sudden load drop indicated in Figure 1. To produce abnormal grains that did not consume the entire specimen gauge region, tensile deformation was halted shortly after DAGG initiation. The specimen was subsequently unloaded and the furnace was turned off to cool the specimen. A software program was used to continuously adjust the cross-head position during cooling to avoid loading the specimen during thermal contraction of the load train. These procedures were intended to aid preservation of the microstructure produced by high-temperature deformation. Although the temperature of the specimen could not be directly monitored during cooling, the furnace control thermocouple indicated a cooling rate of $325 \mathrm{~K} / \mathrm{min}$ in the first two minutes after turning off furnace power.

After the production of abnormal grains by DAGG, specimen microstructures were characterized using optical microscopy, scanning electron microscopy (SEM), electron backscatter diffraction (EBSD) and Laue X-ray diffraction. Specimens were prepared for optical microscopy and Laue X-ray diffraction by mechanical grinding, polishing and subsequent etching in a solution of one part sulfuric acid, one part nitric acid, and one part water, by volume. Both sheet surfaces of the tested Mo sheet specimens were characterized. Specimens were prepared for SEM and EBSD by mechanical grinding, polishing, etching and repolishing for extended times in colloidal silica. The deformed microstructure was characterized by examining material from the specimen deformed gauge region. The undeformed, recrystallized microstructure was characterized by examining material from the specimen grip region. Grain sizes along the tensile direction, $\mathrm{d}_{\mathrm{TD}}$, and the tensile long transverse direction, $\mathrm{d}_{\text {TLTD }}$, of the sheet material were measured using the lineal intercept method [28]. An FEI XL30 ESEM using HKL AZtec software [29] was used to collect EBSD data. EBSD characterization was performed at $20 \mathrm{kV}$ using $8 \times 8$ binning, a Hough space resolution of 60 , a step size of $2 \mu \mathrm{m}$ for the Mo sheet material and a step size of $4 \mu \mathrm{m}$ for the Mo rod material. Using these measurement conditions, the angular accuracy of this system is $\pm 0.5^{\circ}$. Custom Mathematica ${ }^{\mathrm{TM}}[30]$ codes were used to process the EBSD data. The algorithms implemented by Pedrazas et al. [15] were used for grain identification. Grain identification was performed using a minimum grain size of four data points. Adjoining points misoriented by $5^{\circ}$ or 
less were assigned to the same grain.

The dislocation substructure produced during creep deformation of the Mo sheet material was evaluated from EBSD data. The two methods used for this were reference orientation deviation (ROD) and grain orientation spread (GOS). In this study, ROD is defined as the misorientation between each point indexed through EBSD in a grain and that grain's average orientation. A map of ROD values is useful for visualizing dislocation substructure, particularly subgrains, within grains [31]. GOS is defined in this study as the mean misorientation between each point indexed through EBSD in a grain and that grain's average orientation [31]. According to theory, variations between grains in geometrically necessary dislocation density should be reflected by variations in GOS, with increasing geometrically necessary dislocation density generating increasing values of GOS [31]. GOS can thus be used to evaluate the comparative densities of geometrically necessary dislocations.

To determine if preexisting abnormal grains grow by SAGG, specimens containing abnormal grains produced by DAGG were statically annealed. Specimens were suspended from a Mo wire in the middle of the same vacuum furnace used for tensile testing and then statically annealed at 1923 or $2023 \mathrm{~K}\left(1650\right.$ or $\left.1750^{\circ} \mathrm{C}\right)$. Specimens were heated to the desired testing temperature within fifteen minutes and maintained at that temperature for between 10 and 120 minutes. During these annealing treatments, a vacuum of approximately $10^{-3}$ to $10^{-4} \mathrm{~Pa}\left(10^{-5}\right.$ to $10^{-6}$ torr) was maintained. Most specimens were annealed multiple times. The temperature and time of each annealing treatment are provided in Table 3. Because the Mo rod specimen was broken in half during metallography following the initial creation of abnormal grains by DAGG, only half of this specimen was used in subsequent annealing tests. Specimens were etched after each annealing treatment. This etching revealed all abnormal grains and any size changes that occurred in these during annealing. The microstructures of annealed specimens were characterized using SEM and Laue X-ray diffraction.

One Mo sheet specimen containing a preexisting abnormal grain was chosen to investigate if the substructure created by straining prior to DAGG initiation is necessary for the subsequent growth of abnormal grains during DAGG. This specimen was first statically annealed at $1923 \mathrm{~K}$ $\left(1650^{\circ} \mathrm{C}\right.$ ) for only $10 \mathrm{~min}$ to check for the occurrence of SAGG. The specimen was subsequently etched and observed under a microscope to confirm that no growth of its abnormal grain occurred 
during static annealing. This specimen was then annealed for times of 10, 60, and 120 min at $1923 \mathrm{~K}\left(1650^{\circ} \mathrm{C}\right)$, and its microstructure was examined after each static annealing step. The preexisting abnormal grain in this specimen did not grow during any of these static annealing steps. After annealing this specimen for a total of $200 \mathrm{~min}$, the specimen's gauge length, width and thickness were 27.7, 6.2 and $0.50 \mathrm{~mm}$, respectively. The thickness reduction from the asreceived thickness is a result of both tensile deformation during the original creation of an abnormal grain by DAGG and the grinding and polishing of the specimen sheet surfaces for metallographic examination. To investigate whether the preexisting abnormal grain in this annealed specimen would again grow by DAGG, the specimen was subsequently elongated to failure at a true-strain rate of $10^{-4} \mathrm{~s}^{-1}$ and a temperature of $1923 \mathrm{~K}\left(1650^{\circ} \mathrm{C}\right)$.

\section{Results}

\subsection{Abnormal Grains Created by DAGG}

At least one abnormal grain was created by DAGG in each of the Mo tensile specimens. Every abnormal grain identified in each specimen was characterized. The Mo rod specimen was sectioned along its length to identify the abnormal grains produced by DAGG. Thus, only abnormal grains intersecting the sectioned plane could be identified. Five abnormal grains were observed in that section. The crystallographic orientations of three of these abnormal grains were measured using Laue X-ray diffraction. The two other abnormal grains were too heavily deformed for accurate orientation measurement by this technique. These orientation data are plotted on an inverse pole figure (IPF) with respect to the TD in Figure 3(a). Because DAGG grains preferentially grow along the sheet surfaces of the Mo sheet material, a result of the finer grain sizes near the sheet surface in this material [12], both the front and back sheet surfaces of the Mo sheet specimens were examined for abnormal grains. Laue X-ray diffraction was used to index the orientations of DAGG grains on each sheet surface. If two apparent DAGG grains on opposite surfaces had the same orientation, they were assumed to comprise a single DAGG grain spanning the specimen thickness. Different orientations indicated a separate DAGG grain on each surface. For three of the Mo sheet tensile specimens, DAGG produced in each specimen a single abnormal grain that spanned the sheet thickness. These abnormal grains are designated "thickness" abnormal grains.

In the remaining six Mo sheet specimens, DAGG produced abnormal grains that grew along only 
one sheet surface. Three of these specimens each contained a single abnormal grain that grew along only one sheet surface, and the other three each contained two abnormal grains that grew separately along opposite sheet surfaces. Abnormal grains that do not span the sheet thickness are designated "surface" abnormal grains. The measured orientations of abnormal grains in the Mo sheet material are plotted on IPFs with respect to the TD, TLTD, and STD in Figure 3(b). Each abnormal grain measured in each tensile specimen is listed separately in Table 2 along with its characteristics.

To better understand the influence of concurrent plastic deformation on AGG, the boundary migration rates during DAGG were calculated. Although these rates cannot be directly measured from the experiments, the lower limit for the average boundary migration rate of an abnormal grain during DAGG can be calculated. Assuming that all boundaries of the abnormal grain migrated simultaneously during DAGG, the minimum boundary migration rate is half the length of the abnormal grain along the TD divided by the time elapsed between DAGG initiation at $\varepsilon_{\mathrm{c}}$ and DAGG cessation at $\varepsilon_{\mathrm{f}}$. These measurements and the calculated minimum rates are provided in Table 2, except for the abnormal grain observed in specimen Mo S03. The testing data necessary to measure the value of $\varepsilon_{\mathrm{c}}$ for this specimen were not available. In the Mo sheet material, the mean of the minimum boundary migration rates during DAGG at $1923 \mathrm{~K}\left(1650^{\circ} \mathrm{C}\right)$ and a true-strain rate of $10^{-4} \mathrm{~s}^{-1}$ is $45 \mathrm{~mm} / \mathrm{min}$.

\subsection{SAGG of Preexisting Abnormal Grains}

To investigate if preexisting abnormal grains can grow by SAGG at temperatures below $2073 \mathrm{~K}$ $\left(1800^{\circ} \mathrm{C}\right)$, specimens of the Mo rod and sheet materials containing abnormal grains generated by DAGG were statically annealed at 1923 or $2023 \mathrm{~K}\left(1650\right.$ or $\left.1750^{\circ} \mathrm{C}\right)$. The annealing time and temperature of each specimen are provided in Table 3. Preexisting abnormal grains grew by SAGG in three of the Mo sheet specimens, specimens Mo S05, Mo S07 and Mo S08, and one abnormal grain grew in the Mo rod specimen Mo R01. To illustrate growth by SAGG, outlines of the preexisting abnormal grains before and after SAGG are presented in Figure 4. The original DAGG grain is in dark gray, and its growth under SAGG is in light gray. Separate abnormal grains in the sheet specimens are given different number labels. No new abnormal grains were observed in any Mo specimens after static annealing. The orientations of the abnormal grains that grew by 
SAGG are designated in the IPFs of Figures 3(a) and (b).

The growth by SAGG of preexisting abnormal grains provides an opportunity to measure the grain boundary migration rate of abnormal grains in Mo during SAGG independently of initiation. Because the actual time required for a preexisting abnormal grain to grow by SAGG to its final observed state may be less than the total annealing time, only a lower bound on the boundary migration rate during SAGG can be calculated, as previously described for the case of DAGG. This minimum boundary migration rate during SAGG is listed in Table 3 for each case of an abnormal grain that grew during static annealing.

A backscatter SEM image of the interface between an abnormal grain in specimen Mo S07 after growth by SAGG and the remaining polycrystalline microstructure in the gauge region of this specimen is presented in Figure 5. This surface abnormal grain grew by SAGG at $1923 \mathrm{~K}\left(1650{ }^{\circ} \mathrm{C}\right)$ as shown in Figure 4. Following SAGG, the abnormal grain exhibits a uniform interface with no grains from the recrystallized microstructure retained in the abnormal grain, i.e. no island grains. A similar interface is observed between abnormal grains produced by DAGG and the polycrystalline microstructure in this material $[10,11]$.

Table 3 and Figure 4 demonstrate that not all preexisting abnormal grains grew by SAGG. Only four of the eleven preexisting abnormal grain identified in the Mo sheet specimens, approximately one third, grew by SAGG. Only one of the two preexisting abnormal grains in specimen Mo S07 and only one of the five preexisting abnormal grains observed in specimen Mo R01 grew by SAGG. Figure 4 demonstrates that SAGG of the preexisting abnormal grains in Mo S05 and Mo S08 was restricted to the gauge region; growth by SAGG ceased at the transition from the previously deformed gauge region into the undeformed grip region. Prior studies of DAGG noted the same cessation of growth at the transition into the undeformed grip region $[10-12,15]$.

\subsection{DAGG of a Preexisting Abnormal Grain}

Specimen Mo S02 was chosen to investigate if the dislocation substructure created by deformation prior to DAGG initiation is necessary for the subsequent growth of abnormal grains during DAGG. One thickness abnormal grain was produced in this specimen by DAGG during tensile elongation at $1923 \mathrm{~K}\left(1650^{\circ} \mathrm{C}\right)$ and a true-strain rate of $10^{-4} \mathrm{~s}^{-1}$. An image of this preexisting abnormal grain is provided in Figure 6(b). To produce this abnormal grain, tensile deformation was 
halted shortly after DAGG initiation at a true strain of 0.09. Data from this tensile test are presented as true stress versus true strain in Figure 6(a) and labeled as "Halt Test." After microstructural characterization, the specimen was statically annealed at $1923 \mathrm{~K}\left(1650{ }^{\circ} \mathrm{C}\right)$ for a total of $200 \mathrm{~min}$ in four steps, as previously described, to eliminate as much of the dislocation substructure as possible by recovery for this time and temperature. The abnormal grain did not grow during any of these static annealing steps. The specimen was subsequently elongated to failure (EF) at a true-strain rate of $10^{-4} \mathrm{~s}^{-1}$ and a temperature of $1923 \mathrm{~K}\left(1650^{\circ} \mathrm{C}\right)$, the same conditions used to originally produce the abnormal grain by DAGG. Specimen rupture occurred at a total true strain of 0.19. Data from the EF test are labeled in Figure 6(a). Note that these data are reported as true stress versus true strain as calculated without compensation for localized thinning within the abnormal grain as rupture is approached. An image of the specimen after elongation to failure is shown in Figure 6(c). The preexisting abnormal grain in this specimen did not grow measurably during the EF test. All deformation appears to be localized to the abnormal grain, which has a lower flow stress than the surrounding polycrystalline microstructure under the imposed deformation conditions.

\subsection{Microstructure and Crystallographic Texture}

Many of the mechanisms proposed in the literature for SAGG are based on the idea that differences in the mobility of boundaries between grains cause some grains to preferentially grow at the expense of others [3,32-36]. A grain's orientation relative to the majority texture is thought to significantly influence the mobility of its boundaries by controlling boundary character [32]. The orientations measured for individual abnormal grains are provided in Figures 3(a) and (b). To observe the crystallographic textures into which these abnormal grains grew, the polycrystalline microstructures within recrystallized, undeformed specimen grip and deformed specimen gauge regions were characterized. EBSD data from the polycrystalline deformed gauge region in the rod specimen Mo R01 are presented on an IPF with respect to the TD in Figure 7. This specimen was elongated to an engineering strain of $55 \%$ at a true-strain rate of $10^{-3} \mathrm{~s}^{-1}$ at $2023 \mathrm{~K}\left(1750{ }^{\circ} \mathrm{C}\right)$. The hot-deformation texture of the Mo rod material contains a strong $\langle 110\rangle$ fiber texture component. To characterize the hot-deformation texture of the Mo sheet material, EBSD data were collected from the polycrystalline gauge region of specimen Mo S09. This specimen was elongated to a true strain of 0.17 at a true-strain rate of $10^{-4} \mathrm{~s}^{-1}$ and a temperature of $1923 \mathrm{~K}\left(1650^{\circ} \mathrm{C}\right)$. These 
EBSD data are plotted on IPFs with respect to the TD, TLTD and STD in Figure 8. A $\gamma$-fiber, $\langle 111\rangle$ parallel to the STD, and an $\alpha$-fiber, $\langle 110\rangle$ parallel to the TLTD (RD), are observed in the deformed gauge region of this material. EBSD data were also collected from the recrystallized, undeformed grip region of specimen Mo S09. This specimen was at its testing temperature for a total of $77 \mathrm{~min}$. EBSD data from the undeformed grip region of specimen Mo S09 are presented on IPFs in Figure 8. The crystallographic texture in the undeformed grip region is similar to that of the deformed gauge region.

Grain boundary curvature generally drives large grains to consume small grains. Previous investigations of this Mo sheet material indicate that grain growth is insignificant for static annealing across the range of temperatures and times used in this investigation [11, 12]. However, grain size may be altered by tensile deformation. Grain size in the gauge region might thus depend on the strain accumulated during hot-deformation prior to DAGG initiation. To measure the influence of tensile deformation on grain size, the lineal intercept method [28] was used to measure directional grain sizes along the TD, $\mathrm{d}_{\mathrm{TD}}$, and TLTD, $\mathrm{d}_{\mathrm{TLTD}}$, in the undeformed grip and deformed gauge regions of specimen Mo S09 using the EBSD data shown as IPF maps in Figure 9. These directional grain sizes are reported in Table 4. Grains in both the grip and gauge regions of this material are slightly elongated along the TLTD and have similar directional grain sizes. Any grain refinement from hot deformation of the Mo sheet material is less than measurement uncertainty.

EBSD was used to evaluate microstructure within the polycrystalline deformed gauge region of specimen Mo S09 immediately after tensile straining at $1923 \mathrm{~K}\left(1650^{\circ} \mathrm{C}\right)$ and $10^{-4} \mathrm{~s}^{-1}$ to a true strain of 0.17. The microstructure of specimen Mo S06 was also evaluated using EBSD after deformation at $1923 \mathrm{~K}\left(1650^{\circ} \mathrm{C}\right)$ and $10^{-4} \mathrm{~s}^{-1}$ to a true strain of 0.16 and subsequent annealing at $1923 \mathrm{~K}\left(1650^{\circ} \mathrm{C}\right)$ for $130 \mathrm{~min}$. These EBSD data were used to calculate the reference orientation deviation (ROD) and grain orientation spread (GOS). Both measures are useful for evaluating dislocation substructure. Comparisons of data between these two specimens reveal the effects of annealing following hot deformation. A map of ROD values immediately following deformation of specimen Mo S09 is presented in Figure 10(a) and clearly shows evidence of subgrains typical for deformation under five-power creep [37-39]. The average GOS value of grains immediately after deformation is $0.72^{\circ}$, a value that is larger than the measurement uncertainty of $\pm 0.5^{\circ}$. A map of ROD values obtained from the deformed gauge region of specimen Mo S06 after annealing is 
presented in Figure 10(b). The average GOS value of grains in this specimen after hot deformation and subsequent annealing is $0.75^{\circ}$. While the ROD maps of Figure 10 show a clear decrease in the sharpness of subgrains after annealing, significant dislocation substructure is still present after annealing according to the GOS values calculated.

\section{Discussion}

For this study, the initiation and growth of abnormal grains were considered separately. No abnormal grains were initiated by SAGG during static annealing of any Mo specimens. Only DAGG was capable of initiating abnormal grains under the conditions investigated. DAGG was thus used to first create microstructures containing abnormal grains. These microstructures were then used to study the subsequent growth of the abnormal grains under static and dynamic conditions. The results of those experiments are now discussed.

\subsection{Rates of Static and Dynamic Abnormal Grain Growth}

This study provides, for the first time, measurements of the boundary migration rates for abnormal grains during DAGG and SAGG in the same material at the same temperatures. The minimum boundary migration rates measured for abnormal grains under DAGG range from 3 to $255 \mathrm{~mm} / \mathrm{min}$. Among abnormal grains observed to grow under SAGG, the minimum boundary migration rates range from 0.05 to $0.22 \mathrm{~mm} / \mathrm{min}$. The average boundary migration rates measured, when migration occurred, in the Mo sheet material at $1923 \mathrm{~K}\left(1650^{\circ} \mathrm{C}\right)$ under DAGG and SAGG are 45 and $0.1 \mathrm{~mm} / \mathrm{min}$, respectively. Boundary migrations rates for DAGG are approximately two orders of magnitude faster than for SAGG. Although reasons for the extraordinary speed of boundary migration under DAGG are not yet well established, one proposal is that grain-boundary mobility increases through boundary interactions with dislocations generated during plastic flow [11, 40]. This was conceptualized as a mechanism of dislocation assisted unpinning of boundaries during migration, which predicts a boundary migration rate proportional to the strain rate imposed [11]. It is important to note that DAGG initiated and grew abnormal grains in every specimen tested and was the means of creating all the abnormal grains used to investigate SAGG. However, only approximately one-third of these abnormal grains grew by SAGG during subsequent static annealing treatments. The observations of SAGG are discussed next. 


\subsection{Static Growth of Preexisting Abnormal Grains}

Only four of the eleven abnormal grains created by DAGG in the Mo sheet material and only one of the five abnormal grains created by DAGG in the Mo rod material grew by SAGG during static annealing. Thus, only approximately one-third of preexisting abnormal grains grew by SAGG. The presence of dislocation substructure in the polycrystalline deformed gauge region appears to be of importance for those abnormal grains that grew by SAGG. The abnormal grains that grew by SAGG in specimens Mo S05 and Mo S08 ceased growth upon reaching the undeformed grip regions; see Figure 4. This result confirms that a fundamental difference affecting AGG exists between the microstructures of the deformed gauge and undeformed grip regions even after static annealing. Previous investigations determined that DAGG also ceases when an abnormal grain growing in the deformed gauge region reaches the undeformed grip region $[10-12,14,15]$. Figures 8 and 9 and Table 4 demonstrate that neither grain size nor crystallographic texture vary significantly between the grip and gauge regions of this material. However, during the hot deformation necessary to create abnormal grains by DAGG, significant dislocation substructure accumulates in the specimen gauge region. Figure 10(a) shows that a dislocation substructure is retained, primarily observed as subgrains, in the deformed gauge region after tensile straining. Figure 10(b) and the calculations of average GOS values demonstrate that dislocation substructure is not eliminated by static annealing, although the definition of subgrain boundaries is clearly diminished. The exact role of the dislocation substructure during SAGG is not understood [5, 6, 20-22, 40-44], but its presence in the deformed gauge region is the most significant difference observed between the microstructures of the gauge and grip regions. Thus, dislocation substructure is likely necessary for SAGG under the conditions examined. However, since only one-third of the abnormal grains underwent SAGG, a retained dislocation substructure is not alone sufficient to produce SAGG. More specific experimental conditions and microstructural features that correlate with the observations of SAGG are now considered.

The orientation of an abnormal grain relative to the microstructure it borders controls its boundary character, which may significantly influence the abnormal grain's boundary mobility and determine whether or not it grows by SAGG. According to boundary mobility arguments, grains from a minority texture component are more likely to grow abnormally than those from a majority texture component because they will primarily form high-angle grain boundaries with their neighbors [45]. 
If growth by SAGG depends on these differences in grain boundary mobility, then the abnormal grains that grew by SAGG should preferentially grow from minority components of the deformation texture. This is the single case approximately observed in the Mo rod material. Figures 3(a) and 7 demonstrate that the abnormal grain grown by SAGG in the Mo R01 specimen possesses a somewhat minority orientation with respect to the specimen deformation texture. The other abnormal grains indexed in specimen Mo R01, which failed to grow by SAGG, possess orientations nearer the majority in the specimen deformation texture. A different situation is observed for the Mo sheet material specimens. In the Mo sheet material, all of the abnormal grains produced by DAGG are from a majority component of the deformation texture; see Figures 3(b) and 8. Because four abnormal grains in this material grew by SAGG, it is evidently possible for abnormal grains from a majority component of the deformation texture to grow by SAGG. The orientation of an abnormal grain with respect to the surrounding microstructure may influence, but clearly does not determine, if an abnormal grain will grow by SAGG. The failure of abnormal grains in specimens Mo S06 and Mo S07 to grow by SAGG cannot be directly attributed to their orientations. Taken together, these data indicate that the orientation of an abnormal grain relative to the polycrystalline microstructure it consumes, and by inference its boundary character, does not determine whether it will grow by either SAGG or DAGG.

Table 3 demonstrates that no preexisting abnormal grain in the sheet material grew by SAGG when the total true strain applied to initially create that abnormal grain by DAGG was less than 0.15 $\left(\varepsilon_{\mathrm{f}}<0.15\right)$. Among those abnormal grains in the sheet material for which $\varepsilon_{\mathrm{f}} \geq 0.15$, two-thirds grew by SAGG. In the rod specimen Mo R01, for which $e_{\mathrm{f}}=55 \%$ and $\varepsilon_{\mathrm{f}}$ is unknown but certainly greater than 0.15 , one-fifth of the observed abnormal grains grew by SAGG. These data present a clear correlation of SAGG occurring only into those microstructures which experienced the largest plastic strains $\left(\varepsilon_{\mathrm{f}} \geq 0.15\right)$ to create the initial abnormal grain(s) through DAGG. Comparisons made between the deformed gauge and undeformed grip regions of the Mo sheet material demonstrated that deformation of the gauge region changes neither its grain size nor crystallographic texture significantly. However, Figure 10(a) demonstrates that deformation creates a dislocation substructure that includes distinct subgrains. Figure 10(b) demonstrates that static annealing alters but does not eliminate that deformation-induced substructure. This is a possible source for the minimum $\varepsilon_{\mathrm{f}}$ value required to observe SAGG of preexisting abnormal grains. Creep theory provides guidance 
for the evolution of subgrains during high-temperature deformation [37-39]. Commercial-purity Mo sheet material follows the behaviors of five-power creep, also known as dislocation climb controlled creep, typical of pure metals [25]. From an initially recrystallized microstructure, subgrain size $\lambda$ evolves during the initial creep transient and reaches a constant size upon achieving steady state. The steady-state value of $\lambda$ for a material depends on temperature and applied stress or strain rate. While creep testing is often thought of in terms of providing a constant stress to a specimen, which will eventually produce a steady-state creep rate, the same creep theory is equally applicable to the constant true-strain rate applied to specimens for this study, which will eventually produce a steady-state flow stress except when unusual microstructure changes such as DAGG intervene. As steady state is approached during the primary creep transient, subgrain size reduces toward its steady-state value. For a test at constant true-strain rate, the flow stress increases during this subgrain evolution because flow stress is inversely proportional to the subgrain size $\left(\lambda \propto \sigma^{-1}\right)$ [37-39]. This increase in flow stress while approaching a steady-state value is evident in the data of Figure 1, even though DAGG intervenes prior to reaching a steady-state flow stress. Figure 1 suggests that steady state is approached at a true strain of greater than 0.13 . This primary creep region appears as hardening, and it is indeed hardening from the formation of subgrains and their gradual decrease in size toward steady state. The evolution toward finer subgrain sizes during primary creep provides an explanation for the minimum $\varepsilon_{\mathrm{f}}$ value necessary for SAGG of preexisting abnormal grains. The specimens having a larger $\varepsilon_{\mathrm{f}}$ are expected to have finer subgrain sizes in the deformed polycrystalline material. This finer subgrain size, which could lead to a greater density of dislocation substructure retained during static annealing, may enhance SAGG sufficiently for it to grow the preexisting abnormal grains. Important aspects of this explanation, such as a decrease in subgrain size and increase in dislocation substructure density with increasing $\varepsilon_{\mathrm{f}}$, may by directly tested in future investigations.

There remains the question of how a finer subgrain size, or increased dislocation substructure density, might enhance SAGG. The governing mechanisms could contribute either to the driving force for SAGG or to boundary mobility during SAGG, or possibly to both. The classical argument of an increased driving force for migration focuses on a greater system energy reduction with an increasing dislocation density in the polycrystalline microstructure consumed by the abnormal grain [46]. It is also possible that dislocation substructure increases local boundary curvature 
by creating boundary cusps that penetrate at subgrain boundaries [1]. An increased dislocation density in the polycrystalline material consumed might also directly increase boundary mobility by supplying dislocations that interact with the boundary during its migration $[11,40]$.

\subsection{Dynamic Growth of a Preexisting Abnormal Grain}

This study is the first to investigate whether DAGG will resume following static annealing in a microstructure containing an abnormal grain initially created by DAGG. Previous investigations have repeatedly demonstrated in Mo sheet materials that, once initiated, DAGG of abnormal grains will continue throughout the deformed gauge regions of tensile coupons so long as tensile straining continues [10-12, 14, 15]. The abnormal grain created by DAGG in specimen Mo S02 did not continue to grow when straining was resumed after static annealing for $200 \mathrm{~min}$ at the test temperature of $1923 \mathrm{~K}\left(1650^{\circ} \mathrm{C}\right)$. This single data point suggests that the distinct subgrains formed in the polycrystalline microstructure prior to the initiation of DAGG, see Figure 10(a), are very important to DAGG. The recovery and "loosening" of the subgrain structure during annealing, as demonstrated in Figure 10(b), is the most obvious microstructural change to which the failure of DAGG to recur might be attributed. Thus, the dislocation substructure formed during straining prior to the initiation of DAGG appears to be a critical aspect of enabling both SAGG and DAGG of preexisting abnormal grains, with distinct subgrains possibly of particular importance to DAGG.

\section{Conclusions}

Abnormal grains were initiated and grown by DAGG during plastic deformation of commercialpurity Mo materials at temperatures from 1923 to $2073 \mathrm{~K}\left(1650\right.$ to $\left.1800^{\circ} \mathrm{C}\right)$. The subsequent growth of these abnormal grains during static annealing and during continued tensile straining following static annealing was investigated. The following is concluded.

1. Under the conditions examined for this study, abnormal grains were initiated in the two Mo materials only by DAGG. No abnormal grains were initiated by SAGG.

2. When preexisting abnormal grains do grow by SAGG, the rate of boundary migration under SAGG is approximately two orders of magnitude slower than boundary migration during DAGG. These are the first observations of the rates of boundary migration under SAGG and DAGG in the same material at the same temperatures. 
3. Preexisting abnormal grains from both minority and majority texture components were observed to grow by SAGG during static annealing. The crystallographic orientation of an abnormal grain with respect to the polycrystalline microstructure that surrounds it has, at most, a weak effect on its propensity for abnormal grain growth.

4. Preexisting abnormal grains will only grow by SAGG during static annealing when the tensile true strain imposed to create the original abnormal grain(s) under DAGG exceeds a minimum value, which is $\varepsilon_{\mathrm{f}} \geq 0.15$ for the Mo sheet material of this study.

5. The dislocation substructure created by hot tensile straining of polycrystalline material to initiate DAGG in the Mo materials consists of distinct subgrains. Static annealing decreases the sharpness of these subgrains but does not eliminate the dislocation substructure for the conditions applied in this study.

6. The growth of preexisting abnormal grains originally created by DAGG into a polycrystalline microstructure depends strongly on the dislocation substructure in that microstructure. A tight subgrain structure is most advantageous to abnormal grain growth under both static (SAGG) and dynamic (DAGG) conditions. Recovery of a deformed polycrystalline microstructure containing subgrains reduces the propensity for abnormal grain growth.

\section{Acknowledgements}

The authors gratefully acknowledge support from the National Science Foundation for this work under grants DMR-1105468 and DMR-1507417 and for equipment acquired under DMR9974476. The authors also gratefully acknowledge H. C. Stark and Mr. Paul Aimone for generously providing the Mo rod material used for this study. The FEI XL30 ESEM used in this work is from the Department of Geological Sciences at the University of Texas at Austin.

[1] J. G. Byrne, Recovery, Recrystallization, and Grain Growth, The Macmillan Company, New York, 1965, p. 106

[2] F. Humphreys and M. Hatherly, Recrystallization and Related Annealing Phenomena, 2nd ed., Elsevier, New York, 2004, pp. 24-25. 
[3] J. E. May, Trans. Metall. Soc. AIME 212 (1958) 769-781.

[4] W. V. Green, M. C. Smith and D. M. Olson, Trans. Met. Soc. AIME 215 (1959) 1061-1066.

[5] C. Antonione, G. D. Gatta, G. Riontino and G. Venturello, J. Mater. Sci. 8 (1973) 1-10.

[6] G. Riontino, C. Antonione, L. Battezzati, F. Marino and M. C. Tabasso, J. Mater. Sci. 14 (1979) 86-90.

[7] M. L. Briant, F. Zaverl and W. T. Hillert, Acta Metall. Mater. 42 (1994) 2211-2821.

[8] T. Fujii, R. Watanabe, Y. Hiraoka and M. Okada, J. Less-Common Met. 96 (1984) 297-304.

[9] Y. Hiraoka, T. Fujii, T. Kainuma, M. Okada and R. Watanabe, in, K. H. Miska, M. Semchyshen and, E. P. Whelan (Eds.), Physical Metallurgy and Technology of Molybdenum and its Alloys, AMAX, Ann Arbor, MI, 1985, pp. 81-86.

[10] J. Ciulik and E. Taleff, Scr. Mater. 61 (2009) 895-898.

[11] D. L. Worthington, N. A. Pedrazas, P. J. Noell and E. M. Taleff, Metall. Mater. Trans. A 44A (2013) 5025-5038.

[12] P. J. Noell, D. L. Worthington and E. M. Taleff, Metall. Mater. Trans. A 46A (2015) 57085718.

[13] P. J. Noell and E. M. Taleff, Metall. Mater. Trans. A 47A (2016) 5023-5036.

[14] P. J. Noell and E. M. Taleff, JOM 67 (2015) 2642-2645.

[15] N. A. Pedrazas, T. E. Buchheit, E. A. Holm and E. M. Taleff, Mater. Sci. Eng. A 610 (2014) 76-84.

[16] D. Dorner, S. Zaefferer, L. Lahn and D. Raabe, J. Magn. Mater. 304 (2006) 183-186.

[17] C. Musiol, Met. Technol. (London) 3 (1976) 173-182.

[18] J. Dennis, P. S. Bate and J. F. Humphreys, Mater. Sci. Forum 558-559 (2007) 717-722. 
[19] D. Davidson, R. Tryon, M. Oja, R. Matthews and K. R. Chandran, Metall. Mater. Trans. A 38A (2007) 2214-2225.

[20] N. Bozzolo, A. Agnoli, N. Souai, M. Bernacki and R. Logé, Mater. Sci. Forum 753 (2013) $321-324$.

[21] A. Agnoli, M. Bernacki, R. Logé, J. Franchet, J. Laigo and N. Bozzolo, Metall. Mater. Trans. A 46A (2015) 4405-4421.

[22] V. Miller, A. Johnson, C. Torbet and T. Pollock, Metall. Mater. Trans. A 47A (2016) 15661574.

[23] A. D. Rollett, A. P. Brahme and C. Roberts, Mater. Sci. Forum 558 (2007) 33-42.

[24] D. L. Worthington, Characteristics of dynamic abnormal grain growth in commercial-purity molybdenum, PhD Thesis (The University of Texas at Austin, Austin, TX), 2011, pp. 46-88.

[25] J. Ciulik and E. M. Taleff, Mater. Sci. Eng. A 463 (2007) 197-202.

[26] ASTM International, Standard Specification for Molybdenum and Molybdenum Alloy Plate, Sheet, Strip and Foil, Standard Designation B 306-03, ASTM International, West Conshohocken, PA, 2003.

[27] ASTM International, Standard Test Method for Determination of Carbon in Refractory and Reactive Metals and Their Alloys, Standard Designation E 1941-04, ASTM International, West Conshohocken, PA, 2008.

[28] ASTM International, Standard Test Methods for Determining Average Grain Size, Standard Designation E 112-13, ASTM International, West Conshohocken, PA, 2013.

[29] HKL Channel 5, Oxford Instruments PLC, Oxon, United Kingdom, 2007.

[30] Mathematica 8.0, Wolfram Research, Champaign, Illinois, 2010.

[31] S. I. Wright, M. M. Nowell and D. P. Field, Microsc. Microanal. 17 (2011) 316-329.

[32] A. D. Rollett, D. J. Srolovitz and M. P. Anderson, Acta. Metall. 37 (1989) 1227-1240. 
[33] T. Gladman, Mater. Sci. Forum 94 (1992) 113-128.

[34] A. Rollett and W. Mullins, Scr. Mater. 36 (1997) 975-980.

[35] A. Morawiec, Scr. Mater. 43 (2000) 275-278.

[36] Y. C. Zhu, J. H. Mao, F. T. Tan and X. L. Qiao, Appl. Mech. Mater. 127 (2012) 89-94.

[37] O. D. Sherby and P. M. Burke, Prog. Mater. Sci. 13 (1968) 325-390.

[38] O. D. Sherby, R. H. Klundt and A. K. Miller, Metall. Trans. A 8A (1977) 843-850.

[39] J. Lin and O. D. Sherby, Res. Mech. 2 (1981) 251-293.

[40] V. Randle, Mater. Sci. Forum 113 (1993) 189-194.

[41] Y. K. Cho, D. Y. Yoon and M. F. Henry, Metall. Mater. Trans. A 32A (2001) 3077-3090.

[42] S. W. Cheong, E. J. Hilinski and A. D. Rollett, Metall. Mater. Trans. A 34A (2003) 13211327.

[43] S. Wang, Simulation of Abnormal Growth in Subgrain Structures in Deformed Metals, PhD Thesis (Carnegie Mellon University, Pittsburgh, PA), 2010 pp. 6-48.

[44] T. A. Bennett,P. N. Kalu and A. D. Rollett, Microsc. Microanal 17 (2011) 362-367.

[45] F. Humphreys, Acta Mater. 45 (1997) 4231-4240.

[46] G. Gottstein and L. S. Shvindlerman, Grain Boundary Migration in Metals: Thermodynamics, Kinetics, Applications, 2nd ed., CRC press, New York, 2009, pp. 140-144. 
Table 1: The maximum limits reported by the manufacturer for chemical impurities in the powder used to produce the Mo sheet (Mo S) material are listed by weight percent. The concentrations of $\mathrm{C}, \mathrm{N}, \mathrm{O}$ and $\mathrm{S}$ in the Mo sheet material, measured independently using an inert-gas-fusion technique [27], are shown in parts per million (ppm) by weight [12]. The manufacturer's reported chemical composition of the Mo rod (Mo R) material before machining is also shown by weight percent.

\begin{tabular}{cccccccccc}
\hline \multirow{2}{*}{ Mo S } & $\begin{array}{c}\mathrm{Mg} \\
\leq 0.001\end{array}$ & $\begin{array}{c}\mathrm{Mn} \\
\leq 0.001\end{array}$ & $\begin{array}{c}\mathrm{Ni} \\
\leq 0.002\end{array}$ & $\begin{array}{c}\mathrm{Al} \\
\leq 0.002\end{array}$ & $\begin{array}{c}\mathrm{Cu} \\
\leq 0.002\end{array}$ & $\begin{array}{c}\mathrm{Pb} \\
\leq 0.002\end{array}$ & $\begin{array}{c}\mathrm{Ti} \\
\leq 0.002\end{array}$ & $\begin{array}{c}\mathrm{Ca} \\
\leq 0.003\end{array}$ \\
\cline { 2 - 10 } & $\mathrm{Si}$ & $\mathrm{Sn}$ & $\mathrm{Cr}$ & $\mathrm{Fe}$ & $\mathrm{C}$ & $\mathrm{N}$ & $\mathrm{O}$ & $\mathrm{S}$ & Mo \\
& $\leq 0.003$ & $\leq 0.003$ & $\leq 0.005$ & $\leq 0.005$ & $10 \mathrm{ppm}$ & $10 \mathrm{ppm}$ & $40 \mathrm{ppm}$ & $10 \mathrm{ppm}$ & bal. \\
\hline \multirow{3}{*}{ Mo R } & $\mathrm{Mg}$ & $\mathrm{Mn}$ & $\mathrm{Ni}$ & $\mathrm{Al}$ & $\mathrm{Cu}$ & $\mathrm{Pb}$ & $\mathrm{Ti}$ & $\mathrm{Ca}$ \\
& $<0.0010$ & $<0.0010$ & $<0.0010$ & $<0.0010$ & $<0.0010$ & $<0.0010$ & $<0.0010$ & $<0.0010$ \\
\cline { 2 - 10 } & $\mathrm{Si}$ & $\mathrm{Sn}$ & $\mathrm{Cr}$ & $\mathrm{Fe}$ & $\mathrm{C}$ & $\mathrm{Mo}$ & & & \\
& $<0.0010$ & $<0.0010$ & $<0.0010$ & 0.0011 & $<0.0050$ & bal. & & & \\
\hline
\end{tabular}

Table 2: The testing temperature $\left(\mathrm{T}_{\mathrm{DAGG}}\right)$, true-strain rate $(\dot{\varepsilon})$, critical strain at which DAGG initiated $\left(\varepsilon_{\mathrm{c}}\right)$, final true strain $\left(\varepsilon_{\mathrm{f}}\right)$, final engineering strain $\left(\mathrm{e}_{\mathrm{f}}\right)$, type of abnormal grain, abnormal grain length along the TD $\left(l_{D A G G}\right)$, time elapsed during DAGG $\left(t_{D A G G}\right)$ and the lower limit for the minimum boundary migration rate during DAGG $\left(v_{D A G G}\right)$ are provided for each abnormal grain in each specimen. Because specimen Mo R01 necked during testing, true strain for this specimen cannot be accurately calculated.

\begin{tabular}{cccccccccc}
\hline Specimen & $\begin{array}{c}\mathrm{T}_{\text {DAGG }} \\
(\mathrm{K})\end{array}$ & $\begin{array}{c}\dot{\varepsilon} \\
\left(\mathrm{s}^{-1}\right)\end{array}$ & $\varepsilon_{\mathrm{c}}$ & $\varepsilon_{\mathrm{f}}$ & $\begin{array}{c}\mathrm{e}_{\mathrm{f}} \\
(\%)\end{array}$ & Abnormal Grain & $\begin{array}{c}l_{\text {DAGG }} \\
(\mathrm{mm})\end{array}$ & $\begin{array}{c}t_{\text {DAGG }} \\
(\mathrm{s})\end{array}$ & $\begin{array}{c}v_{\text {DAGG }} \\
(\mathrm{mm} / \mathrm{min})\end{array}$ \\
\hline Mo S01 & 2073 & $10^{-4}$ & 0.02 & 0.02 & 2 & thickness & 6.9 & 6 & 34 \\
Mo S02 & 1923 & $10^{-4}$ & 0.09 & 0.09 & 9 & thickness & 12 & 7 & 51 \\
Mo S03 & 1923 & $10^{-4}$ & - & 0.12 & 13 & surface & 5.8 & - & - \\
Mo S04 & 1923 & $10^{-4}$ & 0.13 & 0.13 & 14 & surface 1 & 17 & 2 & 255 \\
& & & & & & surface 2 & 3.3 & 2 & 50 \\
Mo S05 & 1923 & $10^{-4}$ & 0.15 & 0.15 & 16 & thickness & 5.0 & 3 & 50 \\
Mo S06 & 1923 & $10^{-4}$ & 0.16 & 0.17 & 19 & surface & 17 & 203 & 2.6 \\
Mo S07 & 1923 & $10^{-4}$ & 0.18 & 0.18 & 20 & surface 1 & 21 & 43 & 15 \\
& & & & & & surface 2 & 18 & 43 & 13 \\
Mo S08 & 1923 & $10^{-4}$ & 0.19 & 0.20 & 22 & surface 1 & 26 & 178 & 4.4 \\
& & & & & & surface 2 & 22 & 178 & 3.7 \\
Mo S09 & 1923 & $10^{-4}$ & 0.17 & 0.17 & 19 & surface & 18 & 54 & 9.9 \\
Mo R01 & 2023 & $10^{-3}$ & - & - & 55 & abnormal 1 & 6.0 & 40 & 4.1 \\
& & & & & & abnormal 2 & 4.5 & 40 & 3.1 \\
& & & & & & abnormal 3 & 7.1 & 40 & 4.9 \\
& & & & & & abnormal 4 & 7.1 & 40 & 4.9 \\
& & & & & & abnormal 5 & 19 & 40 & 7.1 \\
\hline
\end{tabular}


Table 3: Provided for each specimen are the temperature of static annealing $\left(\mathrm{T}_{\text {anneal }}\right)$, the total true strain used to create the initial abnormal grain $\left(\varepsilon_{\mathrm{f}}\right)$, type of abnormal grain(s) in the specimen, time for each static annealing step $\left(t_{\text {anneal }}\right)$, whether SAGG was observed and the lower bound on the boundary migration rate during SAGG $\left(v_{\mathrm{SAGG}}\right)$.

\begin{tabular}{|c|c|c|c|c|c|c|}
\hline Specimen & $\begin{array}{c}\mathrm{T}_{\text {anneal }} \\
(\mathrm{K})\end{array}$ & $\varepsilon_{\mathrm{f}}$ & Abnormal Grain & $\begin{array}{l}t_{\text {anneal }} \\
(\min )\end{array}$ & SAGG & $\begin{array}{c}v_{S A G G} \\
(\mathrm{~mm} / \mathrm{min})\end{array}$ \\
\hline \multirow[t]{3}{*}{ Mo S01 } & 1923 & 0.02 & thickness & 10 & No & 0.00 \\
\hline & & & & 60 & No & 0.00 \\
\hline & & & & 120 & No & 0.00 \\
\hline \multirow[t]{4}{*}{ Mo S02 } & 1923 & 0.09 & thickness & 10 & No & 0.00 \\
\hline & & & & 10 & No & 0.00 \\
\hline & & & & 60 & No & 0.00 \\
\hline & & & & 120 & No & 0.00 \\
\hline \multirow[t]{3}{*}{ Mo S03 } & 1923 & 0.12 & surface & 20 & No & 0.00 \\
\hline & & & & 40 & No & 0.00 \\
\hline & & & & 120 & No & 0.00 \\
\hline \multirow[t]{3}{*}{ Mo S04 } & 1923 & 0.13 & surface $1 \& 2$ & 30 & No & 0.00 \\
\hline & & & & 60 & No & 0.00 \\
\hline & & & & 120 & No & 0.00 \\
\hline \multirow[t]{2}{*}{ Mo S05 } & 1923 & 0.15 & thickness & 60 & Yes & 0.22 \\
\hline & & & & 60 & No & 0.00 \\
\hline \multirow[t]{2}{*}{ Mo S06 } & 1923 & 0.17 & surface & 40 & No & 0.00 \\
\hline & & & & 90 & No & 0.00 \\
\hline \multirow[t]{2}{*}{ Mo S07 } & 1923 & 0.18 & surface 1 & 90 & Yes & 0.09 \\
\hline & & & surface 2 & 90 & No & 0.00 \\
\hline \multirow[t]{2}{*}{ Mo S08 } & 1923 & 0.20 & surface 1 & 120 & Yes & 0.10 \\
\hline & & & surface 2 & 120 & Yes & 0.06 \\
\hline \multirow[t]{5}{*}{ Mo R01 } & 2023 & - & abnormal 1 & 120 & No & 0.00 \\
\hline & & & abnormal 2 & 120 & Yes & 0.05 \\
\hline & & & abnormal 3 & 120 & No & 0.00 \\
\hline & & & abnormal 4 & 120 & No & 0.00 \\
\hline & & & abnormal 5 & 120 & No & 0.00 \\
\hline
\end{tabular}

Table 4: The directional grain sizes along the TD and TLTD, $\mathrm{d}_{\mathrm{TD}}$ and $\mathrm{d}_{\mathrm{TLTD}}$, of grains in the grip and gauge regions of specimen Mo S09 are provided. This specimen was hot-deformed to a true strain of 0.17 at a true-strain rate of $10^{-4} \mathrm{~s}^{-1}$ and a temperature of $1923 \mathrm{~K}\left(1650^{\circ} \mathrm{C}\right)$. This specimen spent a total of $77 \mathrm{~min}$ at $1923 \mathrm{~K}\left(1650^{\circ} \mathrm{C}\right)$.

\begin{tabular}{rcc}
\hline Location & $\mathrm{d}_{\mathrm{TD}}(\mu \mathrm{m})$ & $\mathrm{d}_{\mathrm{TLTD}}(\mu \mathrm{m})$ \\
\hline Recrystallized, Undeformed Grip Region & $12.7 \pm 2.6$ & $19.3 \pm 3.1$ \\
Deformed Gauge Region & $13.7 \pm 2.7$ & $16.3 \pm 3.1$ \\
\hline
\end{tabular}




\section{Figure Captions}

Figure 1: True-stress versus true strain data from a tensile test of the commercial-purity Mo sheet material are presented. This test was performed at a temperature of $1923 \mathrm{~K}\left(1650^{\circ} \mathrm{C}\right)$ and a truestrain rate of $10^{-4} \mathrm{~s}^{-1}$. Tensile elongation of this specimen was halted shortly after DAGG initiation. An image of the tensile specimen shows the one large abnormal grain produced by DAGG, the DAGG grain.

Figure 2: These schematics demonstrate the orientations of tensile specimens machined from (a) the Mo sheet material and (b) the Mo rod material. The reference axes for the Mo sheet tensile specimens are the tensile direction (TD), the tensile long transverse direction (TLTD) and the short transverse direction (STD). The TD of the Mo sheet material is perpendicular to the final sheet rolling direction (RD). The reference axes for the Mo rod tensile specimen are the tensile direction (TD) and radial direction (RAD).

Figure 3:. The discrete orientations of abnormal grains produced by DAGG in (a) the Mo rod specimen and (b) the Mo sheet specimens are plotted on inverse pole figures (IPFs). The orientations of the abnormal grains that did and did not grow during static annealing are indicated by different symbols.

Figure 4:. Outlines of the abnormal grains in specimens Mo S05, Mo S07, Mo S08 and Mo R01 are shown as initially created by DAGG during hot deformation (Hot Def.) and again after static annealing (Annealed) for the total time indicated. Both sides of each Mo sheet tensile specimen are shown. Black lines indicate the boundaries of the abnormal grains. The thickness grain in Mo S05 is designated TT, and surface grains in other specimens are designated S with an appended number to indicate individual abnormal grains.

Figure 5: A backscatter SEM image from specimen Mo S07 shows the interface between a preexisting abnormal grain that grew by SAGG and the polycrystalline microstructure in the deformed gauge region.

Figure 6: Data from two sequential tensile tests of specimen Mo S02 are provided. Both tensile tests were performed at $10^{-4} \mathrm{~s}^{-1}$ and $1923 \mathrm{~K}\left(1650^{\circ} \mathrm{C}\right)$. Shown are (a) graphs of calculated true 
stress versus true strain from both tensile tests, (b) an image of specimen Mo S02 after elongation to a true strain of 0.09 and (c) an image of specimen Mo S02 after subsequent elongation to failure (EF) following static annealing. The first tensile test is labeled the Halt Test. The second tensile test is labeled the EF test. This specimen was statically annealed at $1923 \mathrm{~K}\left(1650{ }^{\circ} \mathrm{C}\right)$ for a total of 200 min between the two tensile tests.

Figure 7: EBSD orientation data from the deformed gauge region of specimen Mo R01 are shown on an IPF with respect to the TD. This specimen was elongated to an engineering strain of $55 \%$ at a true-strain rate of $10^{-3} \mathrm{~s}^{-1}$ and $2023 \mathrm{~K}\left(1750^{\circ} \mathrm{C}\right)$.

Figure 8: EBSD orientation data from the (top row) undeformed grip region and (bottom row) deformed gauge region of specimen Mo S09 are shown on IPFs with respect to the TD, TLTD and STD. This specimen was elongated to a true strain of 0.17 at a true-strain rate of $10^{-4} \mathrm{~s}^{-1}$ and $1923 \mathrm{~K}\left(1650^{\circ} \mathrm{C}\right)$. This specimen was at its testing temperature for $77 \mathrm{~min}$.

Figure 9:. EBSD data from the (a) recrystallized, undeformed grip and (b) deformed gauge regions of specimen Mo S09 are plotted as inverse pole figure (IPF) maps with respect to the TD. Specimen Mo S09 was tested in tension at $1923 \mathrm{~K}\left(1650^{\circ} \mathrm{C}\right)$ and $10^{-4} \mathrm{~s}^{-1}$. Grain boundaries are shown as black lines.

Figure 10: Reference orientation deviation (ROD) maps are shown for (a) specimen Mo S09 immediately after hot deformation and (b) specimen Mo S06 after hot deformation and static annealing. These specimens were deformed in tension at $1923 \mathrm{~K}\left(1650^{\circ} \mathrm{C}\right)$ and $10^{-4} \mathrm{~s}^{-1}$ to true strains of 0.17 and 0.16, respectively. Specimen Mo S06 was also annealed for $130 \mathrm{~min}$ at $1923 \mathrm{~K}$ prior to acquiring the data shown in (b). Grain boundaries are shown as black lines. 


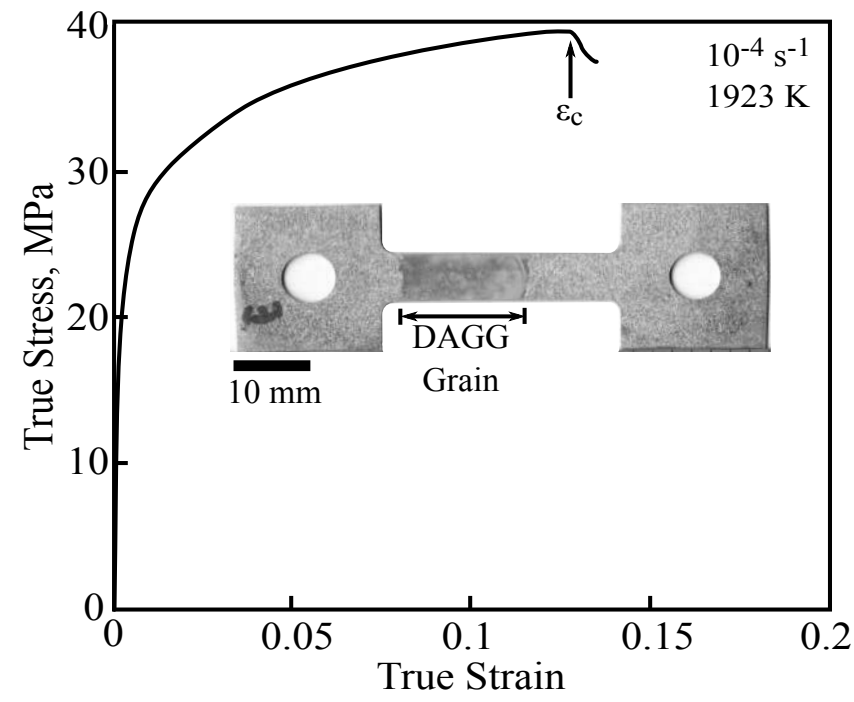

Figure 1: True-stress versus true strain data from a tensile test of the commercial-purity Mo sheet material are presented. This test was performed at a temperature of $1923 \mathrm{~K}\left(1650^{\circ} \mathrm{C}\right)$ and a true-strain rate of $10^{-4} \mathrm{~s}^{-1}$. Tensile elongation of this specimen was halted shortly after DAGG initiation. An image of the tensile specimen shows the one large abnormal grain produced by DAGG, the DAGG grain.

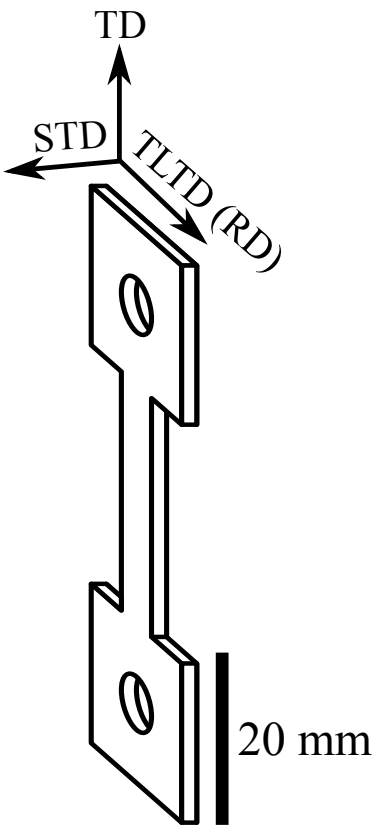

(a)

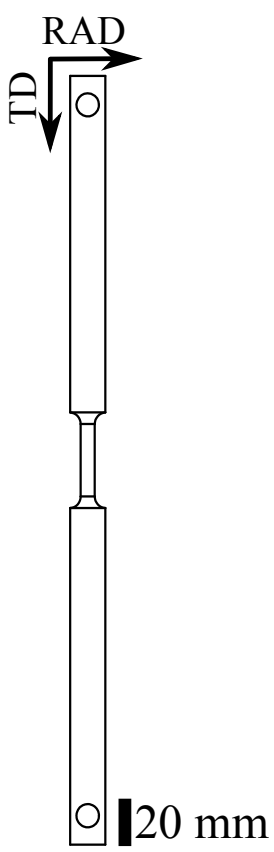

(b)

Figure 2: These schematics demonstrate the orientations of tensile specimens machined from (a) the Mo sheet material and (b) the Mo rod material. The reference axes for the Mo sheet tensile specimens are the tensile direction (TD), the tensile long transverse direction (TLTD) and the short transverse direction (STD). The TD of the Mo sheet material is perpendicular to the final sheet rolling direction (RD). The reference axes for the Mo rod tensile specimen are the tensile direction (TD) and radial direction (RAD). 
(a) Mo R

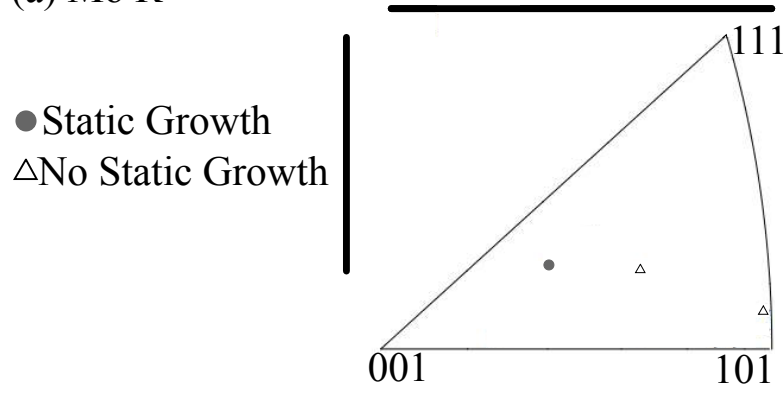

(b) Mo S

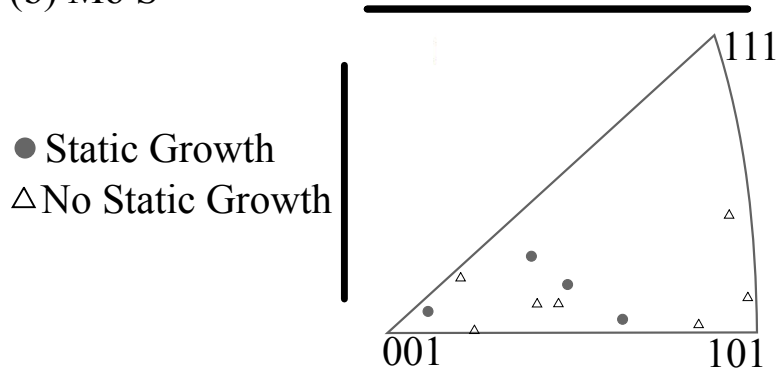

TLTD

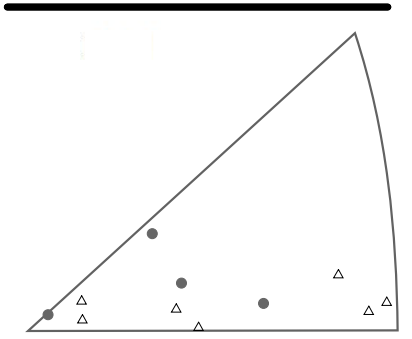

STD

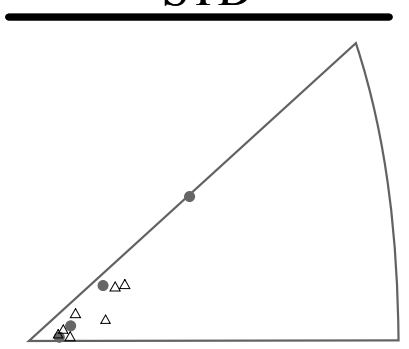

Figure 3: The discrete orientations of abnormal grains produced by DAGG in (a) the Mo rod specimen and (b) the Mo sheet specimens are plotted on inverse pole figures (IPFs). The orientations of the abnormal grains that did and did not grow during static annealing are indicated by different symbols. 
Specimen Mo S05

$1923 \mathrm{~K}$

Hot Def. Annealed
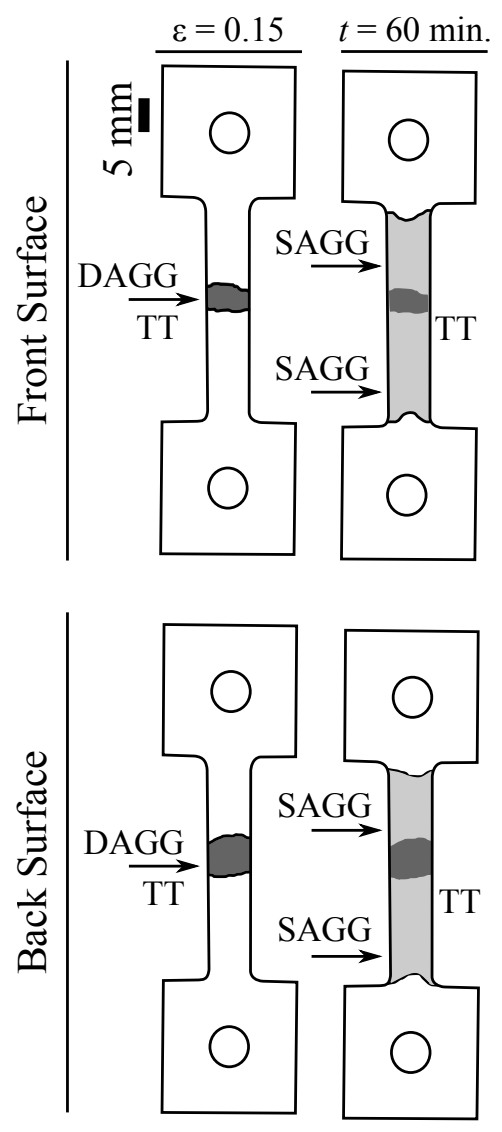

Specimen Mo S07

$1923 \mathrm{~K}$

Hot Def. Annealed

$\underline{\varepsilon}=0.18 \quad t=90 \mathrm{~min}$.
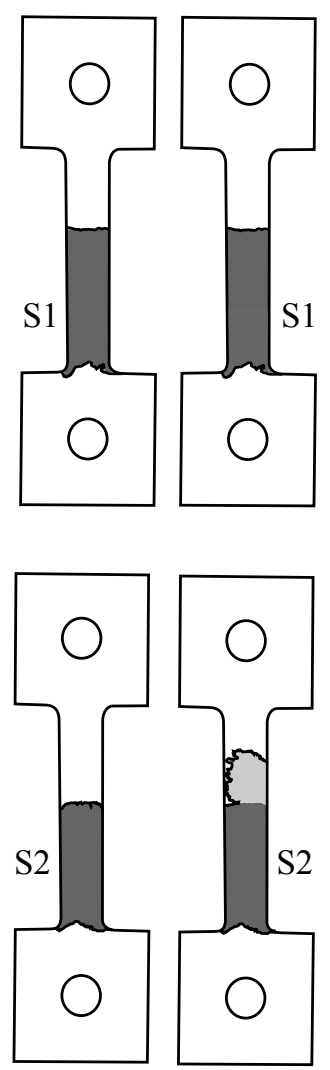

Specimen Mo S08

$1923 \mathrm{~K}$

Hot Def. Annealed

$\underline{\varepsilon=0.20} t=120 \mathrm{~min}$.
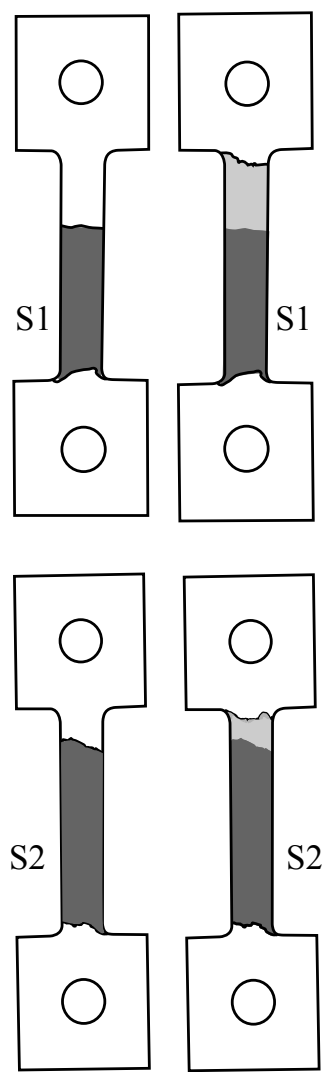

Specimen Mo R01 $2023 \mathrm{~K}$

Hot Def. Annealed $\underline{\mathrm{e}=55 \%} \quad t=120 \mathrm{~min}$.

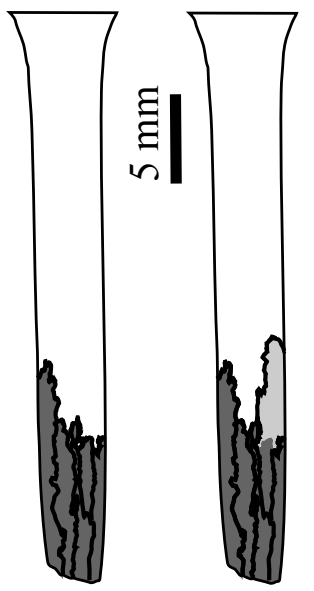

Figure 4: Outlines of the abnormal grains in specimens Mo S05, Mo S07, Mo S08 and Mo R01 are shown as initially created by DAGG during hot deformation (Hot Def.) and again after static annealing (Annealed) for the total time indicated. Both sides of each Mo sheet tensile specimen are shown. Black lines indicate the boundaries of the abnormal grains. The thickness grain in Mo S05 is designated TT, and surface grains in other specimens are designated S with an appended number to indicate individual abnormal grains.

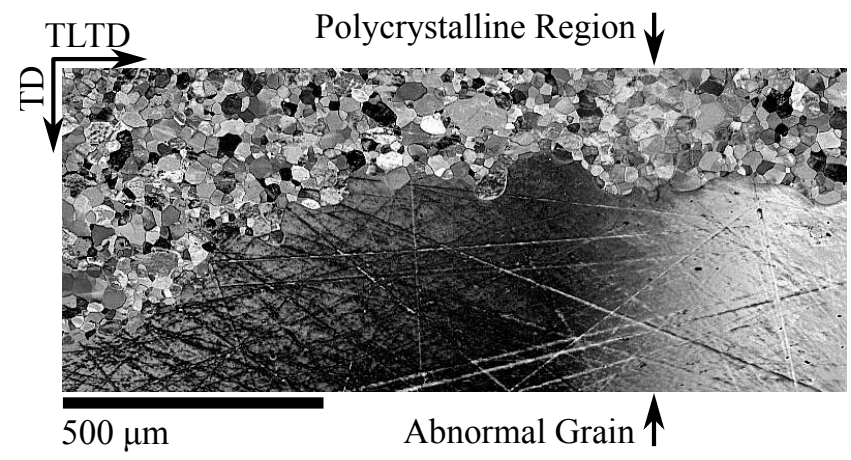

Figure 5: A backscatter SEM image from specimen Mo S07 shows the interface between a preexisting abnormal grain that grew by SAGG and the polycrystalline microstructure in the deformed gauge region. 


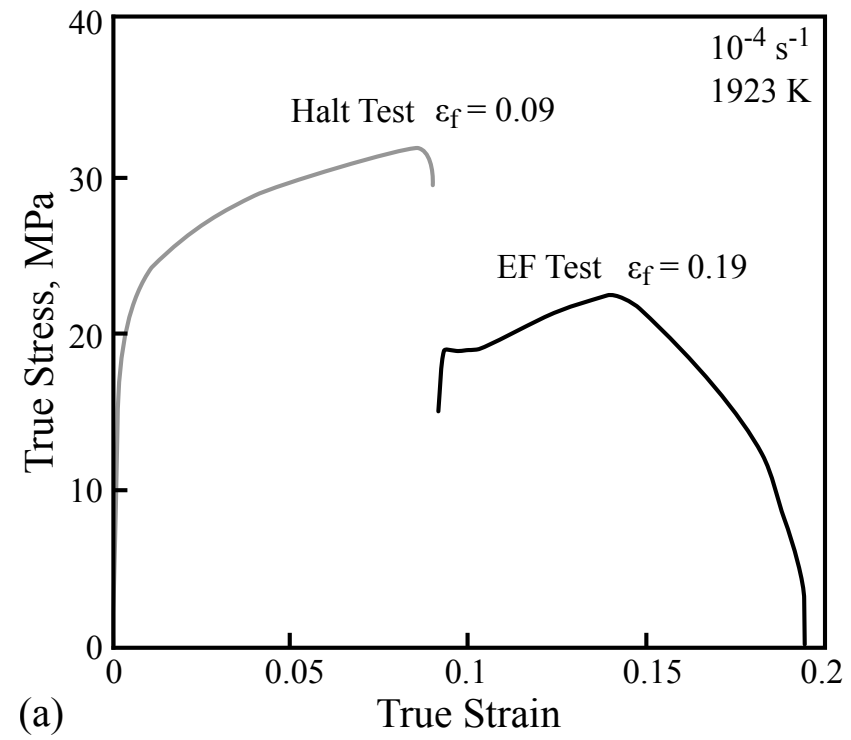

(a)

True Strain

(b)

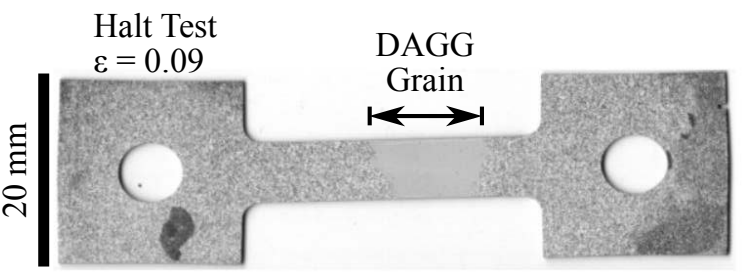

EF Test

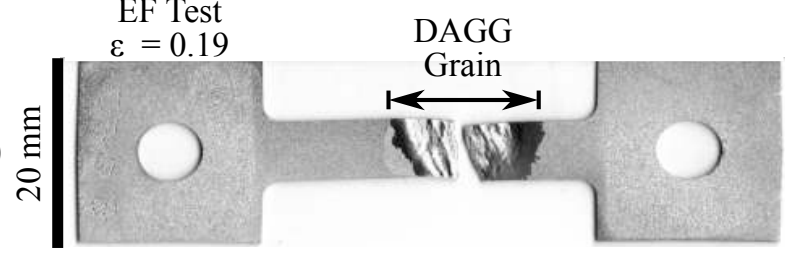

Figure 6: Data from two sequential tensile tests of specimen Mo S02 are provided. Both tensile tests were performed at $10^{-4} \mathrm{~s}^{-1}$ and $1923 \mathrm{~K}\left(1650{ }^{\circ} \mathrm{C}\right)$. Shown are (a) graphs of calculated true stress versus true strain from both tensile tests, (b) an image of specimen Mo S02 after elongation to a true strain of 0.09 and (c) an image of specimen Mo S02 after subsequent elongation to failure (EF) following static annealing. The first tensile test is labeled the Halt Test. The second tensile test is labeled the EF test. This specimen was statically annealed at $1923 \mathrm{~K}\left(1650^{\circ} \mathrm{C}\right)$ for a total of 200 min between the two tensile tests. 


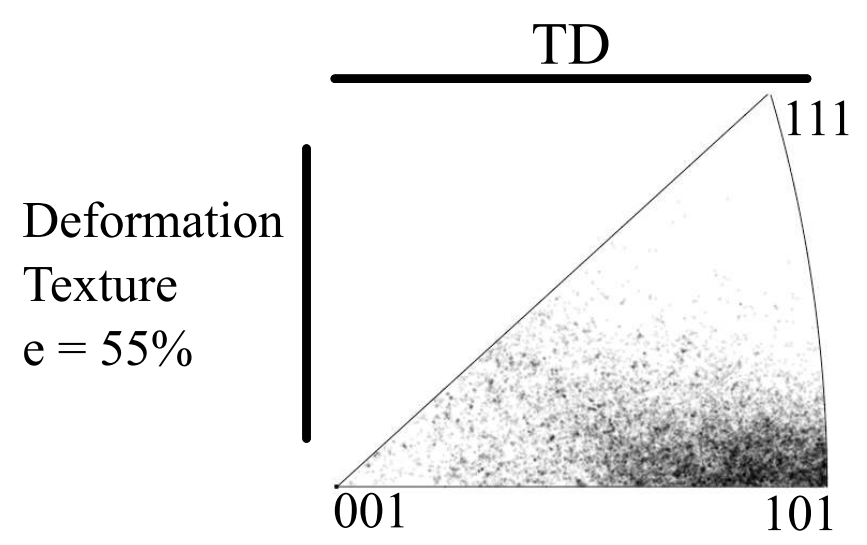

Figure 7: EBSD orientation data from the deformed gauge region of specimen Mo R01 are shown on an IPF with respect to the TD. This specimen was elongated to an engineering strain of $55 \%$ at a true-strain rate of $10^{-3} \mathrm{~s}^{-1}$ and $2023 \mathrm{~K}\left(1750^{\circ} \mathrm{C}\right)$.
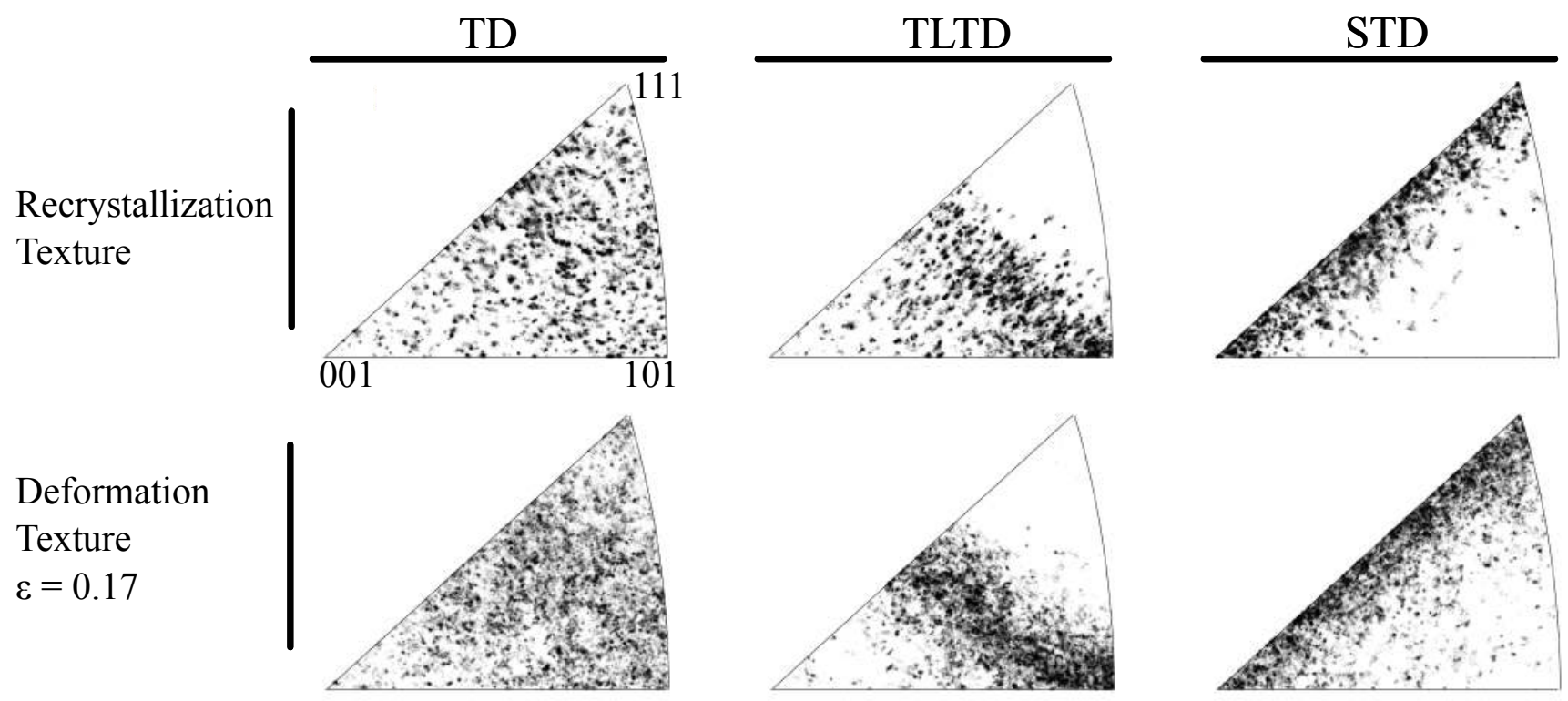

Figure 8: EBSD orientation data from the (top row) undeformed grip region and (bottom row) deformed gauge region of specimen Mo S09 are shown on IPFs with respect to the TD, TLTD and STD. This specimen was elongated to a true strain of 0.17 at a true-strain rate of $10^{-4} \mathrm{~s}^{-1}$ and $1923 \mathrm{~K}\left(1650^{\circ} \mathrm{C}\right)$. This specimen was at its testing temperature for $77 \mathrm{~min}$. 


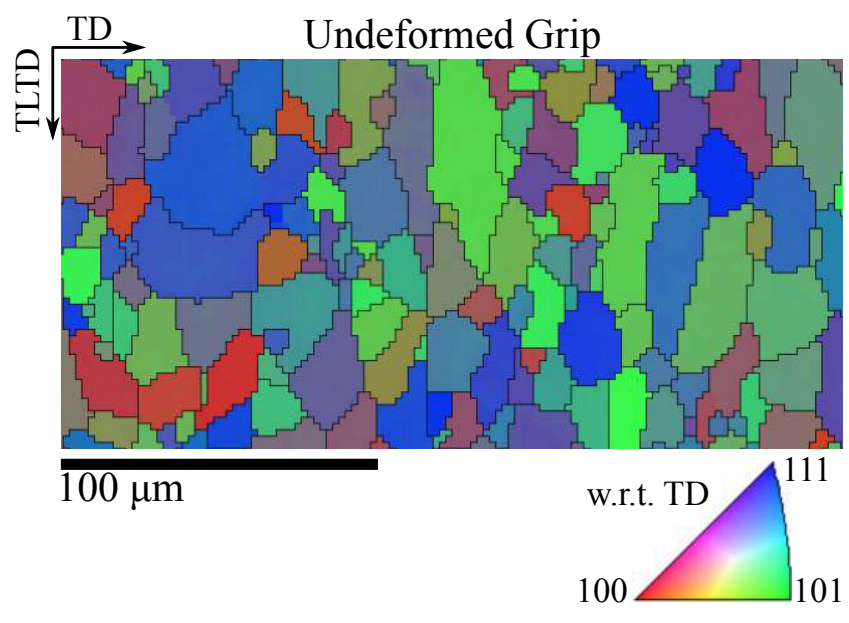

(a)

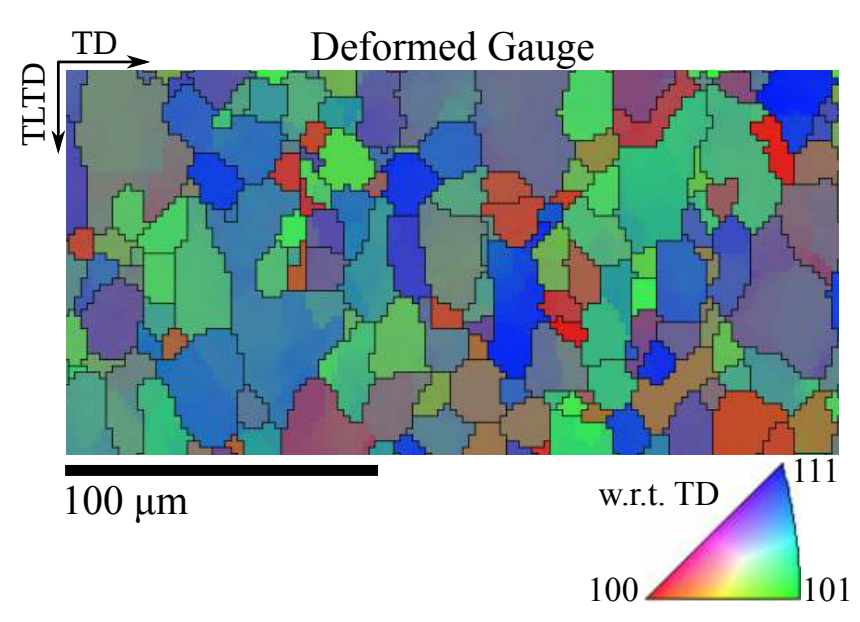

(b)

Figure 9: EBSD data from the (a) recrystallized, undeformed grip and (b) deformed gauge regions of specimen Mo S09 are plotted as inverse pole figure (IPF) maps with respect to the TD. Specimen Mo S09 was tested in tension at $1923 \mathrm{~K}$ $\left(1650^{\circ} \mathrm{C}\right)$ and $10^{-4} \mathrm{~s}^{-1}$. Grain boundaries are shown as black lines.

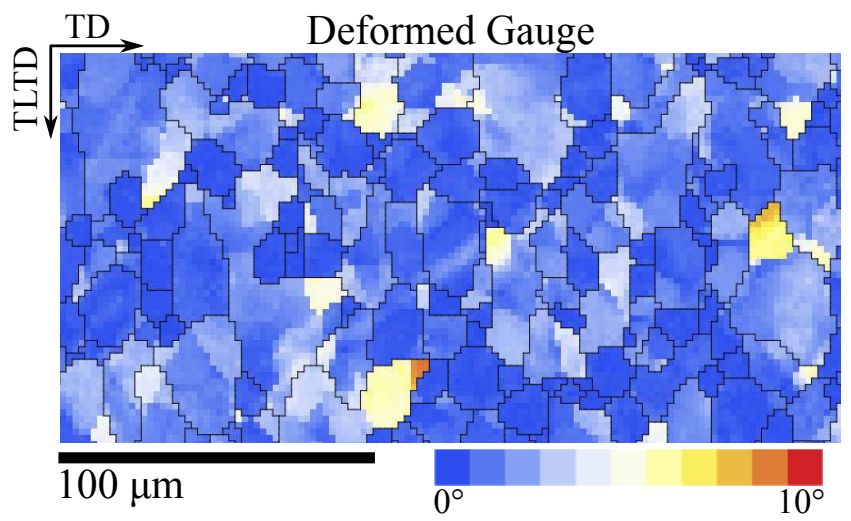

(a)

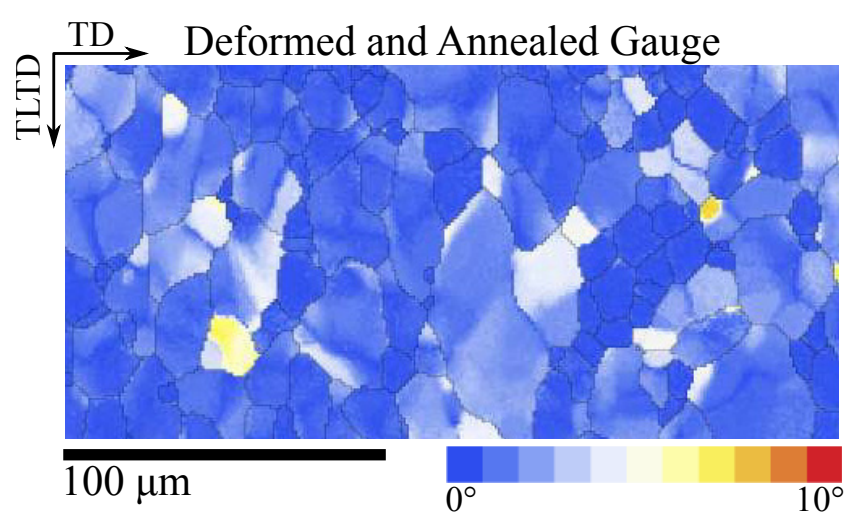

(b)

Figure 10: Reference orientation deviation (ROD) maps are shown for (a) specimen Mo S09 immediately after hot deformation and (b) specimen Mo S06 after hot deformation and static annealing. These specimens were deformed in tension at $1923 \mathrm{~K}\left(1650^{\circ} \mathrm{C}\right)$ and $10^{-4} \mathrm{~s}^{-1}$ to true strains of 0.17 and 0.16 , respectively. Specimen Mo S06 was also annealed for $130 \mathrm{~min}$ at $1923 \mathrm{~K}$ prior to acquiring the data shown in (b). Grain boundaries are shown as black lines. 